\title{
Marjolin's Ulcer: Experience from a Developing Country
}

\section{Sanjay $\mathrm{KY}^{1^{*}}$, Chandan $\mathrm{KJ}^{2}$, Gautam $\mathrm{C}^{3}$, Dipendra $\mathrm{KS}^{3}$, Abhinav $\mathrm{A}^{4}$ and Satish $\mathrm{K}^{3}$}

${ }^{1}$ Department of Endocrine Surgery, SGPGIMS, Lucknow, India

${ }^{2}$ Department of General Surgery, AlIMS, Patna, India

${ }^{3}$ Department of General Surgery, RIMS, Ranchi, India

${ }^{4}$ Department of General Surgery, VMMC, Safdarjung, Delhi, India

\begin{abstract}
Introduction: Marjolin's ulcer (MU) is a rare entity in developed countries, but is relatively common in developing countries due to use of traditional methods of cooking and lack of infrastructure for skin grafting of burn scars. This study was intended to describe the clinicopathologic profile and evaluate the treatment outcome of this condition in our setting.
\end{abstract}

Methods: This was a retrospective study of all histologically confirmed cases of MU, presenting to us from March 2011 to February 2014. Patients with metastatic disease at presentation and those having a follow up of less than 12 months were excluded.

Results: 123 patients were identified and 29 were excluded. Burn was the most common inciting factor (93.6\%) and lower limb was the most common site $(55.3 \%)$ of origin of $\mathrm{MU}$. The mean duration between primary insult and MU was $12.0 \pm 4.3$ years. $74.5 \%$ patients presented with ulcers $>5 \mathrm{~cm}$ in size. $16 \%$ had lymph node metastasis and $16.3 \%$ had distant metastasis at presentation. All but 3.2 patients were treated by wide local excision. $19.1 \%$ patients developed local recurrence and 6.4\% developed distant metastasis during follow up (mean $30.0 \pm 9.2$ months).

Conclusion: Marjolin's ulcers are not rare in our setting and commonly occur in burn scar that was not skin grafted and left to heal secondarily. The most common site of MU is lower limb and the most common histology is SCC. Patients with tumor larger than $5 \mathrm{~cm}$ are more prone to have recurrence and grade III SCC are at more risk of developing distant metastasis.

Keywords: Marjolin's ulcer; Burn scar; Recurrence

\section{Introduction}

Marjolin's ulcer (MU) can be defined as a malignant ulcer arising in a chronically scarred or inflamed skin. It was JN Marjolin who first studied these ulcers and named it "ulcere verruqueux" [1]. But in his original description neither did he mention that these ulcers arise in scars of chronic wounds nor did he mention that these were malignant ulcers. Both these characters were later identified by Robert William Smith but it was not until 1903 when JC Dacosta described these ulcers and coined the term "Marjolin's Ulcer" that this was established as a distinct pathology [1]. Although MU can arise from any chronic wound or non-healing scar, neglected burn scars are the commonest site of its origin [2]. This entity is thought to be rare in developed countries but it is common in developing countries because of a higher incidence of thermal injuries due to use of coal, cow dung cakes, wood and kerosene oil as fuel for cooking. Considering these factors, surgeons in developing countries should be well versed with the management of burn and it's complications including MU. Marjoilin's ulcer is an uncommon but aggressive malignancy that develops in about 1-2\% of burn scars and accounts for about $1 \%$ of all skin cancers $[3,4]$. In the majority of cases, the MU is a squamous cell carcinoma (SCC) but other histological types of skin malignancies have been described including basal cell carcinoma (BCC), melanoma and sarcomas. MUs contribute to an overall $2 \%$ of all SCCs and $0.03 \%$ of all basal cell carcinomas of the skin [5]. The aim of this study was to review our institutional experience of MU as we see it more commonly as compared to our western counterparts

\section{Methods}

This is a retrospective analysis of a prospectively maintained data at the department of General Surgery of Rajendra Institute of Medical Sciences, Ranchi, Jharkhand, India over a period of three years. A total of 123 consecutive patients of MU diagnosed in our hospital in the study period (March 2011 to February 2014) were identified for inclusion in this study. After confirmation of the diagnosis by biopsy all patients underwent staging with a contrast enhanced computerized tomography (CECT) imaging of the local site, ultrasound (USG) of the regional lymph node (LN) basin, USG abdomen and X-ray chest. Any suspicious lymph nodes seen on USG were aspirated for cytology and suspicious findings on X-ray chest or USG abdomen were confirmed by CECT chest/ abdomen and pelvis. 20 patients with distant metastases were excluded from the study. We also excluded 9 patients whose follow up data was not available for analyses. Records of the remaining 94 patients who were managed by us and had followed up with us for a minimum of 1 year were analyzed. All statistical analyses were performed using SPSS (version 16.0; SPSS Inc, Chicago, Illinois). The $\chi 2$ test, Fisher's exact test, t-tests and Mann-Whitney tests were used to analyze the variables. All P-values of less than 0.05 were considered to be statistically significant.

\section{Results}

The mean age was $53.72 \pm 11.3$ yrs (range $25-78$ years) and male to female ratio was $1.8: 1$. Vast majority of our patients, $82(87.2 \%)$ came from the rural areas. Most common mode of primary injury was thermal injury (flame burn in $70.2 \%$, scald in $21.3 \%$ and electric burn in $2.1 \%$ ) followed by trauma in $4.3 \%$ (Table 1 ). Only 4 (4.3\%) patients had received a skin graft for management of primary injury. Duration

${ }^{*}$ Corresponding author: Sanjay KY, Senior Resident, Department of Endocrine Surgery, SGPGIMS, Lucknow, India, Tel: 918127095090; E-mail: sky1508@gmail.com

Received November 17, 2017; Accepted November 27, 2017; Published December 05, 2017

Citation: Sanjay KY, Chandan KJ, Gautam C, Dipendra KS, Abhinav A, et al 2017) Marjolin's Ulcer: Experience from a Developing Country. Surgery Curr Res 7: 303. doi:10.4172/2161-1076.1000303

Copyright: @ 2017 Sanjay KY, et al. This is an open-access article distributed under the terms of the Creative Commons Attribution License, which permits unrestricted use, distribution, and reproduction in any medium, provided the original author and source are credited. 


\begin{tabular}{|c|c|}
\hline Characteristics & Frequency (percentage) \\
\hline \multicolumn{2}{|l|}{ Mode of primary injury } \\
\hline Flame burn & $66(70.2)$ \\
\hline Scald & $20(21.2)$ \\
\hline Electric burn & $02(02.1)$ \\
\hline Trauma & $04(04.3)$ \\
\hline Diabetic ulcer & $02(02.1)$ \\
\hline \multicolumn{2}{|l|}{ Site of ulcer } \\
\hline Lower limb & $52(55.3)$ \\
\hline Upper limb & $25(26.6)$ \\
\hline Trunk & $12(12.8)$ \\
\hline Scalp & $05(05.3)$ \\
\hline \multicolumn{2}{|l|}{ Tumor size } \\
\hline$<5 \mathrm{~cm}$ & $24(25.5)$ \\
\hline $5-10 \mathrm{~cm}$ & $44(46.8)$ \\
\hline$>10 \mathrm{~cm}$ & $26(27.7)$ \\
\hline Lymph node metastasis & $15(16.0)$ \\
\hline Distant metastasis at presentation" & $20(16.3)$ \\
\hline \multicolumn{2}{|l|}{ Primary surgical procedure } \\
\hline Wide excision & $91(96.8)$ \\
\hline Amputation & $03(03.2)$ \\
\hline Lymph node dissection@ & $15(16.0)$ \\
\hline \multicolumn{2}{|l|}{ Histological subtype } \\
\hline Squamous cell carcinoma & $85(90.4)$ \\
\hline Basal cell carcinoma & $08(08.5)$ \\
\hline Melanoma & $01(01.1)$ \\
\hline \multicolumn{2}{|l|}{ Grade of SCC $(n=85)$} \\
\hline 1 & $32(37.6)$ \\
\hline II & $41(48.3)$ \\
\hline III & $12(14.1)$ \\
\hline
\end{tabular}

Note: \#Out of 123 diagnosed cases of MU, 20 had distant metastasis at presentation and was not included in analysis. @12 patients underwent inguinal LND while 3 patients underwent axillary LND.

Table 1: Clinico-pathological characteristics.

between primary injury and diagnosis ranged from 3 to 22 years with a mean of $12.0 \pm 4.3$ years. Lower limb was the most common site $(55.3 \%)$ followed by upper limb (26.6\%), trunk (12.8\%), and scalp in $5.3 \%$ (Table 1). In our series the tumor size was less than $5 \mathrm{~cm}$ in $24(25.5 \%)$, 5 to $10 \mathrm{~cm}$ in $44(46.8 \%)$ and more than $10 \mathrm{~cm}$ in $26(27.7 \%)$ patients (Table 1). The incidence of lymph node metastasis in our series was $16 \%$ $(n=15)$. Although we did not analyze the results of patients with distant metastasis because these patients were not finally managed by us, the incidence of distant metastasis at presentation seen in our study was 16.3\%. 96.8\% $(n=91)$ of our cases were treated with wide local excision while 3 required amputation, all below knee, for tumors involving the bone. Since we did not had the facility for margin evaluation by frozen section analysis at our institute, we attempted to obtain a wide macroscopic circumferential margin of at least $2 \mathrm{~cm}$ and even wider, wherever possible. In all our cases the horizontal margins were found to be free of tumor infiltration, but in 4 cases the deep resection margin was found to have microscopic infiltration. In all these cases a re-excision of the involved margin had to be done. In $90.4 \%$ cases the final histopathological diagnosis was squamous cell carcinoma, in $8.5 \%$ it was BCC while in $1.1 \%$ it was melanoma. None of our patients received radiotherapy or chemotherapy. 12 patients underwent inguinal LN dissection while 3 had an axillary LN dissection for LN metastasis. All these patients had LN metastasis on preoperative evaluation by cytology of LNs and it was confirmed on HPE examination of the LND specimen. Our mean follow up was $30.0 \pm 9.2$ months with a minimum follow up duration of 12 months required for inclusion in the study. $19.1 \%(n=18)$ patients developed local recurrence. 17 recurrences were from SCC (7 each from grade I and grade II and 3 from grade
III tumor) and 1 was a BCC. $6.4 \%(n=6)$ patients developed distance metastasis during the follow-up.

\section{Discussion}

Estimated incidence of MU varies in different series, but mostly it is thought to be rare with incidence being in the range of $1-2 \%[6,7]$. The most common inciting injury in various studies has been the thermal injury and it stands true in our study as well [2]. Although no age is immune to development of MU, it has been reported that the latency period between the initial insult and development of MU is inversely proportional to the age at initial insult [8]. The mean latency period in our study was $12.0 \pm 4.3$ years which although falls within the range reported in literature but this is also because the range reported in literature is too wide. In fact the latency period seen in our study is much less than the average of 35 years reported by other researchers [5]. Most authors agree that excision of the burn scar and skin grafting can prevent development of MU but management of large number of thermal burns is a problem in developing countries due to high burden of thermal burns and relative lack of facilities for grafting. This fact is represented in our study where only $4.5 \%$ of the patients suffering a burn injury had skin grafting. No association was seen in our study between the mode of injury and histologic type of cancer arising in it $(\mathrm{p}=0.782$ ). As like other studies, the most common site of MU in our study was lower limb. The second most common site in our study was upper limb which is in contradiction to other studies in which head and neck is the most common site after lower limb [9-11]. In our study regional lymphadenopathy was found in $16 \%$ cases by combining clinical examination with routine USG evaluation of regional LN basin. This rate is somewhat lower than the range of $20-36 \%$ reported from other studies [9]. In fact the LN metastasis reported in literature varies widely, with some studies have reported LN metastasis in more than $60 \%$ cases [10]. Most common histological type in most series including ours is SCC which accounted for $90.4 \%$ cases in our series which is a bit higher than most series where it constitutes about $70-90 \%$ of the ulcers $[9,11]$. Intraoperative frozen section analysis of the resected margins has been suggested as an useful tool to know the status of the resected margins and guide the surgeon in further management [12]. These ulcers usually require wide area of skin excisions and hence need some form of resurfacing (split/ full thickness skin graft or flap). In case the final histopathology shows any of the margins to be involved, contemplation of a repeat excision means loss of the graft/ flap as well. We did not have frozen section analysis available at our institute and hence we routinely performed split thickness skin grafting (SSG) and no flaps were used. Also, because a SSG allows for early detection of recurrences it has been preferred by most researchers for resurfacing of the defects. All of our margin positive cases were SCC and in each case the deep margin showed microscopic invasion by tumor. We excised an additional centimetre of the issue and were able to obtain a clear margin, but this clearly is not the ideal way to deal with these aggressive malignancies and we would certainly like to have frozen section available for margin assessment to facilitate a single stage management. Some authors suggest sentinel lymph node biopsy (SLNB) and even routine prophylactic LN dissection for these malignancies [13]. Although we did therapeutic LN dissection in 15 cases for cases which had LN metastasis confirmed on preoperative evaluation, none of our patients underwent any form of prophylactic LN surgery and none had any recurrence in regional LNs during the follow up. Recurrences are not uncommon and an incidence of $14-33 \%$ been reported in literature $[11,14]$. $19.1 \%$ patients in our study developed local recurrence. No recurrences were seen in tumors that were $<5 \mathrm{~cm}$ while 9 recurrences were observed in each of the other groups. While a tumor size $>5 \mathrm{~cm}$ was 
significantly associated with recurrence $(\mathrm{p}=0.008)$, histological subtype $(\mathrm{p}=0.777)$, site $(\mathrm{p}=0.425)$ and grade of SCC $(\mathrm{p}=0.466)$ were not. 6 of our patients developed distant metastasis and 3 of those developed it within $1 \mathrm{yr}$ of surgery. These 3 patients expired within 6 months of diagnosis of metastatic disease. One interesting finding in our study was that none of the patients who had metastasis had local recurrence. All metastases were from grade III SCC and 2 of them occurred in tumors $<5 \mathrm{~cm}, 3$ in $5-10 \mathrm{~cm}$ group and 1 in $>10 \mathrm{~cm}$ case. Histological subtype $(\mathrm{p}=0.712)$, tumor size $(\mathrm{p}=0.800)$ and site of disease $(\mathrm{p}=0.138)$ was not associated with distant metastasis but grade III SCC was strongly associated with higher chances of developing distant metastasis $(\mathrm{p}<0.001)$.

\section{Conclusion}

Marjolin's ulcers are not rare in our setting and commonly occur in burn scar is not skin grafted and left to heal secondarily. The most common site of MU is lower limb and the most common histology is SCC. Patients with tumor larger than $5 \mathrm{~cm}$ are more prone to have recurrence and grade III SCC are at greater risk of developing distant metastasis.

\section{Conflict of Interest}

SKY and other co-authors declare no conflict of interest, financial or otherwise.

\section{References}

1. Cruickshank AH, Gaskell E (1963) Jean-Nicolas Marjolin Destined to be forgotten? Med Hist 7: 383-384.

2. Kerr-Valentic MA, Samimi K, Rohlen BH, Agarwal JP, Rockwell WB (2009) Marjolin's ulcer: Modern analysis of an ancient problem. Plast Reconstr Surg 123: 184-191.
3. Kannan RY, Rauf GK (2010) Acute burn scar basal cell carcinoma. Ann Plast Surg 64: 321-322.

4. Ozercan IH, Okur MI, Coskun F, Yildirim AM (2004) Malignant fibrous histiocytoma and squamous carcinoma derived from a burn scar. Acta Chir Belg 104: 745-747.

5. Saaiq M, Ashraf B (2014) Marjolin's ulcers in the post-burned lesions and scars World J Clin Cases 2: 507-514.

6. Duncan KO, Leffell DJ (2003) Fitzpatrick's dermatology in general medicine (6th edn.). McGraw-Hill, New York.

7. Thio D, Clarkson JH, Misra A, Srivastava S (2003) Malignant change after 18 months in a lower limb ulcer: Acute Marjolin's ulcer revisited. Br J Plast Surg 56: 825-828.

8. Copcu E, Aktas A, Sişman N, Oztan Y (2003) Thirty-one cases of Marjolin's ulcer. Clin Exp Dermatol 28: 138-141.

9. Kowal-Vern A, Criswell BK (2005) Burn scar neoplasms: A literature review and statistical analysis. Burns 31: 403-413.

10. Sadegh FM, Lebaschi AH, Hajirostam M, Keramati MR (2013) Marjolin's ulcer Clinical and pathologic features of 83 cases and review of literature. Med $J$ Islam Repub Iran 27: 215-224.

11. Oruç M, Kankaya Y, Sungur N, Özer K, Işık VM, et al. (2017) Clinicopathological evaluation of Marjolin ulcers over two decades. Kaohsiung J Med Sci 33: 327-333.

12. Ghalambor A (2007) Marjolin ulcer: How much of safety margin needs resection along marjolin ulcer squamous cell carcinoma in recurrence cases. Pak J Med Sci 23: 394-397.

13. Asuguo M, Ugare G, Ebughe G, Jibril P (2007) Marjolin's ulcer: The importance of surgical management of chronic cutaneous ulcers. Int J Dermatol 46: 29-32.

14. Chalya PL, Mabula JB, Rambau P, Mchembe MD, Kahima KJ, et al. (2012) Marjolin's ulcers at a university teaching hospital in Northwestern Tanzania: a retrospective review of 56 cases. World J Surg Oncol 10: 38. 